\title{
1 An Assessment of the Potential of Supply-side Ventilation Demand Control to 2 Regulate Natural Ventilation Flow Patterns and Reduce Domestic Space Heating Consumption

Uncontrolled natural ventilation systems tend, by their nature, to deliver varying flow rates that are not necessarily optimised for human comfort or energy efficiency. Moreover these ventilation flow rates may not be delivered along the intended flow paths through a building, possibly further reducing ventilation effectiveness and increasing ventilation heat losses. These characteristics make natural ventilation systems a suitable candidate for ventilation demand control where the levels of fresh air delivered respond to a sensed parameter that indicates the level of ventilation demand. This paper makes a preliminary, comparative assessment of the impact an active supply-side $\mathrm{CO}_{2}$ ventilation demand control system may have on the ventilation regime, flow levels and space heating consumption of a two-storey naturally ventilated domestic property. The dwelling is modelled in EnergyPlus and the performance of the ventilation demand control system simulated using EnergyPlus' run-time Energy Management System. Simulations are conducted for a variety of temperate climate contexts and building fabric leakage levels. The simulations demonstrate that the ventilation demand control system could reinforce desired flow regimes and provide comparable indoor air quality compared to the uncontrolled base case whilst delivering significant reductions in space heating consumption.

7 Keywords: passive ventilation, ventilation demand control, Smart Home,

\section{Introduction}

In climates that can result in a significant building heating season, ultra-low energy housing ${ }^{1}$ is not generally considered possible with natural, or passive, ventilation. The environmental driving forces for passive ventilation (ambient temperature and wind pressure differentials) are highly variable, often over very short time scales, resulting in variable background ventilation flow rates that if too high can cause excessive ventilation heat loss and discomfort, and if too low can cause poor Indoor Air Quality (IAQ) and overheating. In more complex or multi-storey dwellings flow paths may also not be as intended, routing too little or much ventilation through particular areas of a building. These factors, coupled with a lack of heat recovery, makes it difficult for an uncontrolled passive ventilation system to consistently deliver the high levels of energy efficiency and IAQ required for ultra-low energy housing.

The type of domestic ventilation regime considered here is the only natural ventilation system still explicitly considered to comply in the latest revision of the UK building regulations [2] and is termed Passive Stack Ventilation (PSV) [3]. PSV consists of ducts that run from the wet rooms (kitchens, bathroom, toilets) to the roof line. The act of buoyancy, and low pressures generated at the roof line by wind action, draws air through the ducts and out of the wet rooms, lowering their pressure, which in turn draws air from the neighbouring dry rooms (living room, bedrooms) which in turn draw air through the periphery of the building; often via trickle ventilators situated within the window

\footnotetext{
${ }^{*}$ Corresponding author

Email address: R.Southall@brighton.ac.uk (R.G. Southall)

${ }^{1}$ Taken here to mean a dwelling with space heating consumption below 15 kilo-watt hours per square metre floor area per annum $\left(\mathrm{kWh} / \mathrm{m}^{2} \cdot \mathrm{a}\right)$ as, for example, mandated by the PassivHaus standard [1]
} 
frames and via air leakage through the building fabric. Buoyancy acts to increase stack flow rates with increasing temperature difference between inside and outside and flow therefore tends to be higher with lower ambient temperatures. Stack flow also increases with the lower roof line pressure caused by wind action and therefore flow also generally increases with higher wind speeds. The pressure difference the stacks can generate is also related to their vertical travel distance and their cross-sectional area, and the building regulations contain stipulations for the latter.

In an 'ideal' situation (figure 1a) each trickle vent on each floor would consistently provide an appropriate incoming ventilation rate. The variable nature of the natural driving forces does however mean that a reliable ventilation level is unlikely to be supplied if no control is applied. Even a time averaged flow rate may not be optimal due to specifics of the building configuration and PSV system installation coupled with the particulars of the climate. In addition to the intended flow regime potentially not providing consistent and optimal flow rates to each zone of a building, different flow regimes could develop. For example, as a stairwell can act, in effect, as a very large cross-sectional area stack, fresh air entering the building on the ground floor may find a less resistive path to outside by passing up the stairwell and exiting through the stacks on the upper floor (figure 1b) rather that exiting the building through the ground floor stacks. This flow regime may reduce or even reverse the incoming ventilation on the first floor. Also, if higher wind speeds generate significant pressure differentials between the windward and leeward side of the building, excess ventilation could be forced through the trickle ventilators/fabric on the windward side causing reduced or reversed flow through the ventilators/fabric on the leeward side (figure 1c) i.e. the building cross-ventilates.

Any reversed flow through the ventilators/fabric is an issue as it becomes an uncontrolled ventilation egress point. Whilst the PSV extract system is sized to attempt to provide suitable ventilation rates, if air egresses the building via other means, this appropriate sizing becomes, in part, redundant and the building could significantly over ventilate with an attendant energy penalty in cold weather.

In reality flow patterns will be a mix of these and other flow regimes that will be heavily dependant on the building configuration, environmental driving forces and occupant behaviour e.g. opening windows. In this context it is difficult for a PSV system to either be energy efficient or an effective guarantor of IAQ without regulating flow rates by using, for example, ventilation demand control.

The technical performance requirements for supplying ventilation to ultra-low energy homes has instead been met by mechanical ventilation with heat recovery (MVHR) systems, which use heat recovery to minimise ventilation heat losses and a closed loop mechanically driven system to ensure ventilation levels and IAQ. MVHR has now become the primary ventilation solution for ultra-low energy housing and is even mandated by standards such as PassivHaus [4]. Passive ventilation can however offer some distinct advantages over mechanical ventilation systems: quiet operation, low maintenance, low embodied energy, low capital cost, lower running cost, no supply side ducting, easier retrofit and intuitive cooling control via the opening of windows that would otherwise make it a good candidate for ultra-low energy housing.

At least some of the weaknesses of passive systems could be addressed if the flow rates delivered were tailored dynamically to the needs of the occupants and the building. In the same way that modern, smart thermostats can sense and be programmed to control a building's temperature to reduce energy consumption, a smart passive ventilation system could intelligently modify the supplied airflow rates depending on the ventilation requirement of the building. Ventilation heat losses would be reduced by reducing ventilation levels when not required, and IAQ maintained by making sure the system is fully available when ventilation is required.

Such a system, termed here Demand Controlled Passive Ventilation (DCPV), is already commercially available in a limited form as a whole-house natural ventilation system with both supply side and extract side control using passive humidity reactive grills and ventilators. This paper explores a potential further development in this field, made viable by recent developments in the technologies that underpin the Internet of Things (IoT) and Smart Home concepts, by simulating a PSV system with facade ventilators that electronically sense indoor ventilation demand, and change their opening area accordingly.

To perform an initial assessment of the performance of a DCPV system a typical two-story house, with levels of 


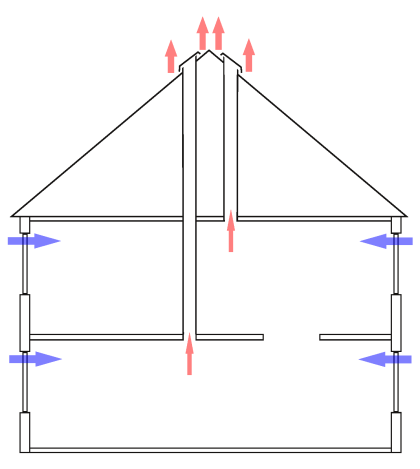

(a) 'Ideal' operation

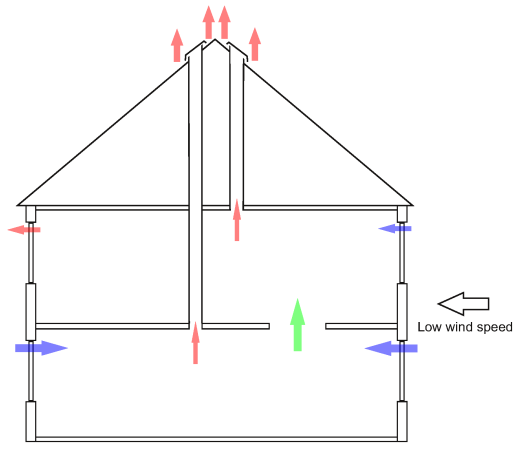

(b) Unintended stairwell stack flow

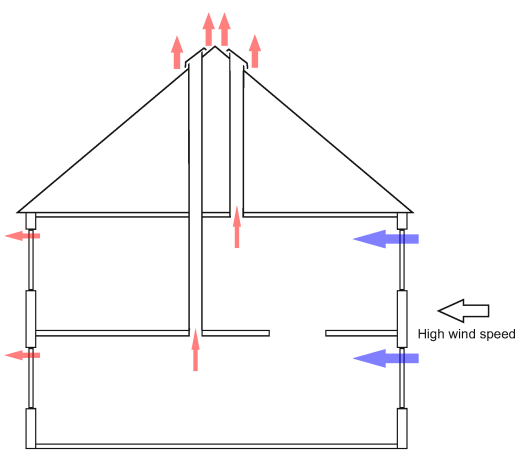

(c) Unintended cross-ventilation

Figure 1: Typical PSV extract system

insulation suitable for a low energy home, has been modelled with the 3D design package Blender ${ }^{2}$ and simulated with the building performance simulation software EnergyPlus [5] under three different climate contexts. The VI-Suite [6] addon for Blender has been used to convert Blender geometry and materiality to the EnergyPlus input format. An EnergyPlus airflow network [7, 8] has been employed to simulate the entire natural ventilation system including flow through the stacks, facade ventilators and 4 different levels of fabric air-leakage. EnergyPlus' Energy Management System[9] (EMS) module has been employed to control the opening of the facade ventilators in response to internal $\mathrm{CO}_{2}$, temperature and humidity. Results are generated for both the DCPV and PSV systems and ventilation flow rates, IAQ and space heating consumption figures are compared.

\section{Simulation Methodology}

\subsection{Climate}

Natural ventilation systems that do not moderate the supply air temperature are most suited to climates with mild winter temperatures that are less likely to cause poor thermal comfort resulting from the ingress of very cold air. These milder winter conditions are typical in maritime climates such as the European Environment Agency's "Atlantic" climate zone shown in figure 2. A more refined subdivision [10,11] of Europe's mid-latitude maritime climate results in three sub-zones: "Lusitania" covering Northern Portugal/Spain and Western France; "Atlantic Central" covering Southern UK, Northern France and Belgium; "Atlantic North" covering Northern UK, Holland, North West Germany and Western Scandinavia. Three locations, one in each these sub-zones, have therefore been selected (figure 2a) to cover a range of climates potentially suitable for an un-moderated natural ventilation system: Porto (Lusitania) in Northern Portugal, Plymouth (Atlantic Central) in South West England, Bergen (Atlantic North) in South West Norway. EnergyPlus weather files for Porto and Bergen were taken from the EnergyPlus weather database website ${ }^{3}$. For Plymouth a typical reference year climate file was taken from the University of Exeter's Prometheus website ${ }^{4}$. Box-and-whisker plots (with whiskers at the $0.5^{\text {th }}$ and $99.5^{\text {th }}$ percentiles) of ambient temperatures and wind speeds are shown in figure $2 \mathrm{~b}$. Porto has the warmest temperatures and lowest wind speeds, Plymouth has the windiest conditions and Bergen the coldest temperatures.

\footnotetext{
${ }^{2} \mathrm{http}: / /$ www.blender.org

${ }^{3}$ https://energyplus.net/weather

${ }^{4}$ http://emps.exeter.ac.uk/engineering/research/cee/research/prometheus/
} 


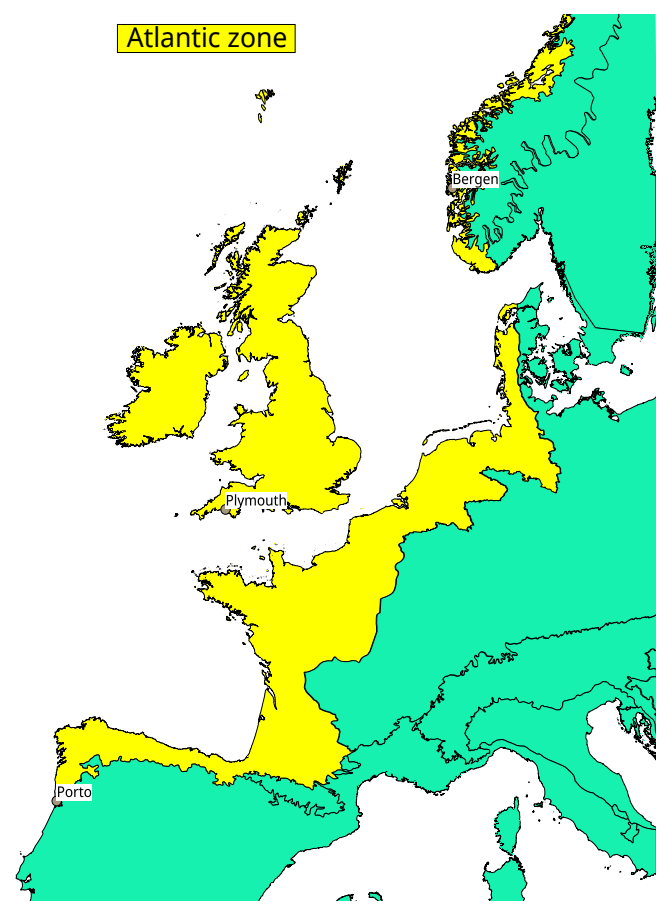

(a) Climate locations
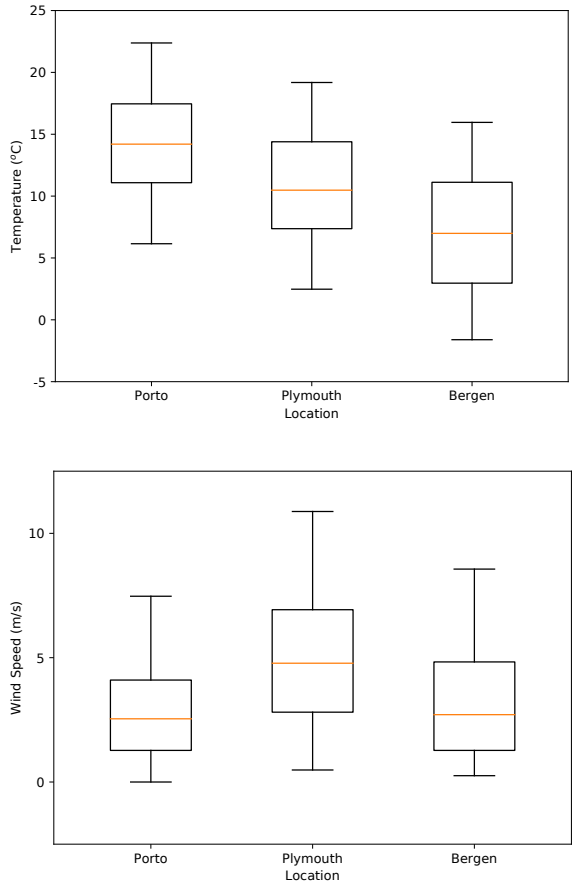

(b) Climate metrics

Figure 2: Simulation climates

\subsection{Building Model}

The dimensions of the house floor plan are $9 \times 6 \mathrm{~m}$ with a floor to ceiling height of $2.85 \mathrm{~m}$. The construction of the building is based on a typical lightweight insulated panel solution (U-Value $0.113 \mathrm{~W} / \mathrm{m}^{2} \cdot \mathrm{k}$ ) with triple glazed, lowE, argon filled windows (U-Value $0.77 \mathrm{~W} / \mathrm{m}^{2} \cdot \mathrm{k}$ ) which conform to the high standards of insulation required for low energy homes. Westerly glazing areas are minimised and southerly glazing shaded to reduce summer overheating. The basic Blender geometry model is shown in figure 5. Shading surfaces (coloured red in figure 5) around windows have been included to mimic shadowing due to the relatively thick walls needed for the high wall insulation levels.

The building is split into two thermal/airflow zones: a ground floor zone considered to contain kitchen/living areas and a first floor zone considered to contain bathroom/bedrooms. Occupancy is assumed to be two adults and two children. Modelled occupancy patterns for each hour of the day are shown in figure 3. Occupancy in the ground floor zone is predominantly during the evenings and Sundays, and at night times on the first. Each occupant is specified to have a metabolic rate of $80 \mathrm{~W}$ (taken as an average of adult $\&$ child) and a $\mathrm{CO}_{2}$ production rate of $3.82 \mathrm{E}-8 \mathrm{~m} / \mathrm{s} \cdot \mathrm{W}$ (the default value in EnergyPlus based on ASHRAE Standard 62.1-2007). In this initial study no other internal sources of pollutant, such as moisture or formaldehyde, have been modelled. In addition to the occupant heat gains, equipment gains have been specified for the building at $2.1 \mathrm{~W} / \mathrm{m}^{2}$ of floor area as specified in the PassivHaus [4] standard. Heating is provided with an EnergyPlus IdealLoadSystem[7] which supplies the heating loads based on an ideal heating system. The IdealLoadSystem, although air-based, is modelled as a closed-circuit and does not provide any fresh air ventilation to the house. The heating thermostat is set to a constant $20^{\circ} \mathrm{C}$.

To this building model a PSV system with fabric trickle ventilators, sized according to the current UK building regulations, has been incorporated using EnergyPlus' airflow network system. The airflow network approach has been shown to produce very good agreement to experimental data when simulating a range of natural ventilation strategies $[12,13,14]$ and has been used to simulate the $\mathrm{CO}_{2}$ based control of window opening in commercial buildings[15]. For this airflow network, nodes are created representing the ground and first floor thermal zones, and the 
ambient conditions around the house. These airflow nodes are connected to each other with airflow components such as cracks, windows or Effective Leakage Areas (ELAs) and the law of mass conservation solved for all the nodes at each simulation time step. The airflow network used here is without distribution i.e. no air handling units are included and ventilation flow rates are purely a result of buoyancy and wind pressure differentials.
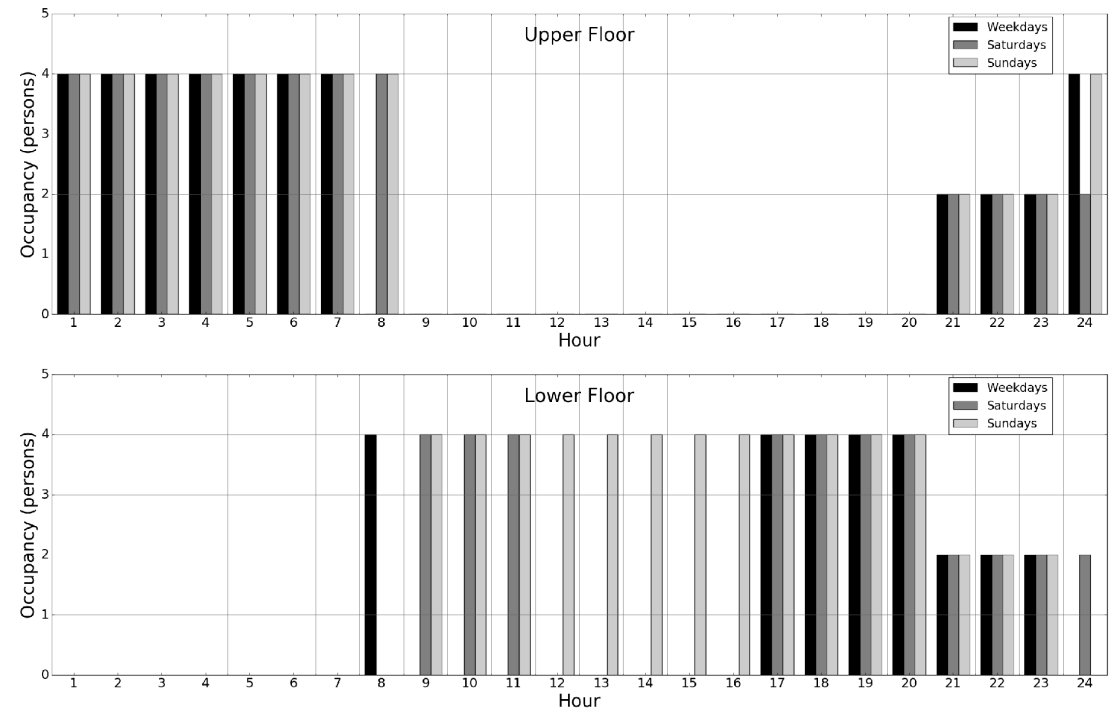

Figure 3: Simulated Occupancy Levels

Although a high degree of fabric air-tightness is recommended for energy efficient homes: less than 0.6 ACH@ $50 \mathrm{PA}^{5}$ is required by the PassivHaus[1] standard for example, it is not necessarily achieved. A study of new-build UK homes [16] fitted with MVHR, which requires a high degree of air-tightness for optimal performance, demonstrated a variety of fabric leakage rates. Whilst some of the houses in the meta-study exhibited air leakage rates as high as $9 \mathrm{~m}^{3} / \mathrm{hr} \cdot \mathrm{m}^{2}$ ${ }^{6}$, the majority (85\%) were below $6 \mathrm{~m}^{3} / \mathrm{hr} \cdot \mathrm{m}^{2}$ which equates to 2.7ACH@50Pa for the house modelled here. Fabric leakage ratings of 0.6, 1, 2 and 3ACH@50PA have therefore been considered here.

The airflow network has been used to model these fabric air-leakages by the specification of ELA flow components embedded within the external surfaces of the house that connect the interior and exterior airflow nodes. The overall ELA for the whole house at each of the different air-tightness levels is calculated according to equation 1 [17]. The ELA for each wall is calculated by area weighting this overall ELA and then applied to each external wall by associating an ELA flow component with one of the geometric faces that make up the wall (figure 5). Faces close to the vertical mid-point of the wall have been chosen. Only leakage through the external walls has been considered here.

$$
E L A\left(m^{2}\right)=\kappa \cdot P_{r}^{n-1 / 2} \cdot \sqrt{\frac{\rho}{2}}
$$

where $\rho$ is air density (taken to be $1.2 \mathrm{~kg} / \mathrm{m}^{3}$ ),

$\mathrm{P}_{r}$ is the reference pressure $(50 \mathrm{~Pa})$,

$\mathrm{Q}_{l}$ is the building leakage flow rate in $\mathrm{m}^{3} / \mathrm{s} @ 50 \mathrm{~Pa}$ (converted from the ACH@50Pa value),

$\mathrm{n}$ is the flow exponent (taken as 0.65 [18])

and $\kappa$ is the building leakage coefficient, itself derived from $\kappa=\mathrm{Q}_{l} / \mathrm{P}_{r}{ }^{n}$

\footnotetext{
${ }^{5}$ Air changes per hour at 50Pa pressure difference

${ }^{6}$ Metres cubed per hour per metre squared of external wall area at 50Pa pressure difference
} 
The passive stacks have also been modelled with the airflow network according to the latest revision of the UK building regulations[2], which specifies stacks with a minimum internal diameter of $125 \mathrm{~mm}$ and a cross-sectional area of $12,000 \mathrm{~mm}^{2}$. Using the ceiling to roof line heights from the building model the stack pressure difference for the ground and first floor was calculated[19, equation 3.13] and these calculated pressures applied to the simple opening flow equation[19, equation 3.1] using the stack cross-sectional area of $12,000 \mathrm{~mm}^{2}$ to determine theoretical flow rates through the stacks. Applying the calculated stack pressure differences to the EnergyPlus crack flow equation a close fit (figure 4) to the stack flow rates is achieved with a crack flow coefficient and exponent of 0.013 and 0.5 respectively. Stacks have therefore been modelled in EnergyPlus as crack flow components at the roof line with these values. Stack duct losses are not considered here and the stack installation is thus considered to be optimal i.e. ducts run vertically and are flat sided.

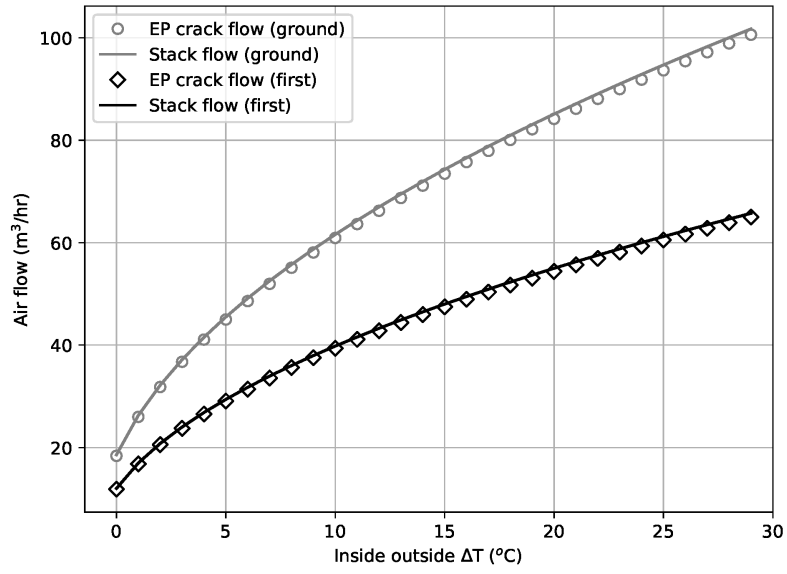

Figure 4: Theoretical stack and modelled crack flow rates

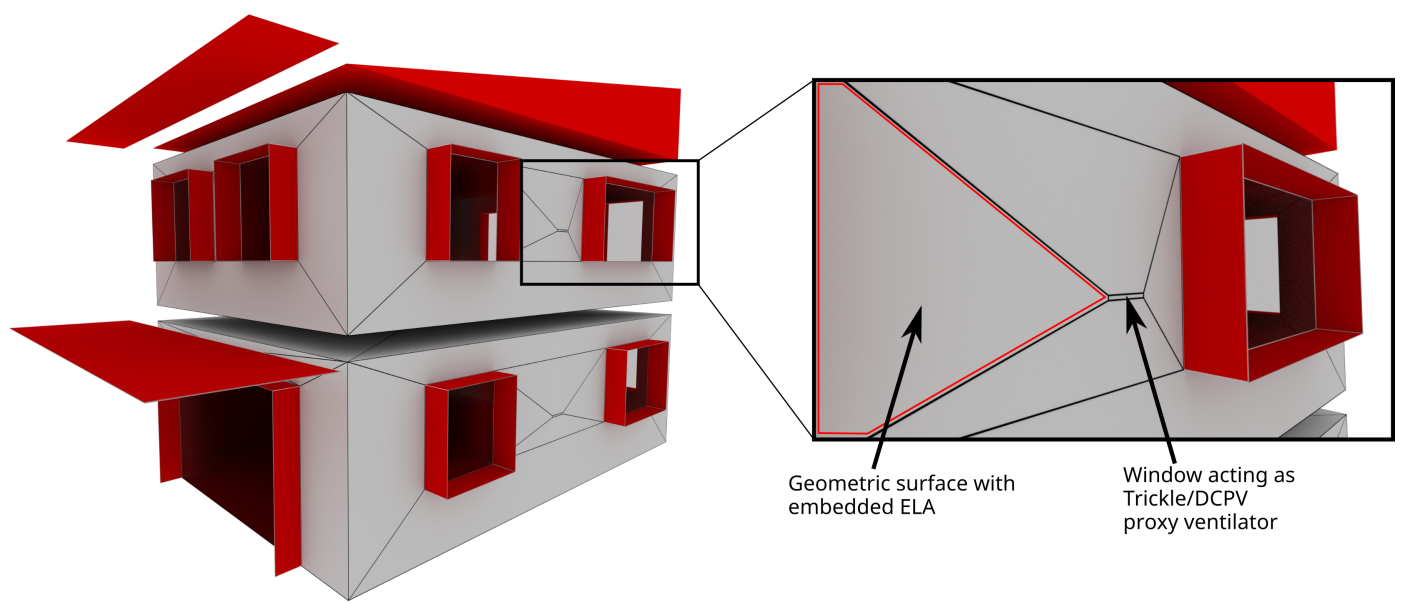

Figure 5: EnergyPlus building model (shading surfaces shown in red) with ventilator and leakage flow components

A stairwell connecting the ground and first floor zones has been modelled with a horizontal opening component. This opening is permanently open with an opening area of $1.5 \mathrm{~m}^{2}$.

The empirical equation developed by Swami \& Chandra[20] has been used to calculate the wind pressure coefficients for the external wall and roof airflow nodes as it has been shown to provide good agreement[21] to wind tunnel 
tests for the simple, low-rise building profile modelled here. The building is modelled with a sheltered 'City' exposure, which acts to moderate the calculated wind pressure differentials around the building.

\subsection{Trickle/DCPV Ventilators}

Current UK building regulations [2] also specify the total equivalent area of the trickle ventilators, which for the house modelled here is $72,000 \mathrm{~mm}^{2}$, from which $6,000 \mathrm{~mm}^{2}$ is deducted due to the presence of the stacks. The remaining $66,000 \mathrm{~mm}^{2}$ is split equally across the eight external wall sections resulting in $8,250 \mathrm{~mm}^{2}$ of ventilator area per external wall section. This equal division of ventilation area across all walls ensures ventilator flow is not prejudiced towards certain wind directions.

The supply side ventilator control of the DCPV system is simulated with the EMS module of EnergyPlus. The EMS module allows the creation of sensors within the house that can control an actuator at each time step of the simulation according to relationships defined with EnergyPlus' run-time language (ERL). In the simulations presented here the sensors created with the EMS are the zone $\mathrm{CO}_{2}$, temperature and humidity level. As of EnergyPlus version 8.6, the EMS actuator that can control ventilation rates in an airflow network model is the opening factor of windows and doors. Windows have therefore been specified within each external wall section (figure 5) of the model, as a proxy for the ventilators, each with an openable area of $8250 \mathrm{~mm}^{2}$ in accordance with the building regulation. The proxy ventilators are placed at the mid-point of each facade section (figure 5) where possible or above the conventional windows/doors if not. These proxy ventilators can thus modify their opening area in response to the values from the room sensors.

\begin{tabular}{|c|c|}
\hline Model parameter & EnergyPlus specification \\
\hline \hline Period & Whole year \\
\hline Time steps per hour & 12 \\
\hline Exposure & City \\
\hline Wind pressure coefficients & Swami \& Chandra surface average equation for low-rise buildings \\
\hline Solar & Full interior and exterior \\
\hline Walls & Light weight plywood \& EPS panel (U-Value $\left.0.11 \mathrm{~W} / \mathrm{m}^{2} \cdot \mathrm{k}\right)$ \\
\hline Windows & Triple glazed, argon fill (U-Value $\left.0.77 \mathrm{~W} / \mathrm{m}^{2} \cdot \mathrm{K}\right)$ \\
\hline Heating & Unlimited ideal load system (air based, closed loop) \\
\hline Heating set-point & Constant $20^{\circ} \mathrm{C}$ \\
\hline Ventilation \& Infiltration & Airflow network without distribution \\
\hline Stacks & Crack flow $(0.013$ coefficient, 0.5 exponent) components at the roof line \\
\hline Ventilators & Proxy windows at the vertical midpoint (where possible) of external walls \\
\hline PSV ventilator control & Always fully open \\
\hline DCPV ventilator control & Fully open if zone temperature $>24^{\circ} \mathrm{C}$ or $\mathrm{RH}>70 \%$ or $\mathrm{CO}_{2}>800 \mathrm{ppm}$ \\
\hline Infiltration points & ELA flow components placed near the vertical mid-point of external walls \\
\hline
\end{tabular}

Table 1: EnergyPlus parameters

Although recommendations for internal $\mathrm{CO}_{2}$ level have existed for more than 100 years [22] there are no commonly accepted standards for recommended $\mathrm{CO}_{2}$ levels in domestic buildings. The European Standard EN 13779 [23] for non-domestic buildings does state that moderate IAQ corresponds to indoor $\mathrm{CO}_{2}$ levels between 600 and $1000 \mathrm{ppm}$, and ASHRAE states [24] that an internal $\mathrm{CO}_{2}$ level less than 700ppm above ambient (or 1100ppm) is likely to produce a comfortable environment in terms of odour/bio-effluent. Both the upper (1000ppm) [25] and lower (600ppm) [26] limits of the EN 13779 standard have been used as the switching point for $\mathrm{CO}_{2}$ based mechanical ventilation demand control and significant research has also gone into the optimisation of ventilation demand control algorithms [27]. In this initial natural ventilation study the mid-point of the EN 13779 range (800ppm) has been used as a simple ventilation demand control switching point. In terms of the EMS specification the DCPV system ventilators are set to be completely open once the associated zone $\mathrm{CO}_{2}$ goes above $800 \mathrm{ppm}$, and completely closed when below. In addition, the vents are set to be fully open if the zone temperature goes above $24^{\circ} \mathrm{C}$ or the zone $\mathrm{RH}$ goes above $70 \%$ irrespective 
of zone $\mathrm{CO}_{2}$ level. The proxy ventilators for the PSV system are controlled in a similar manner except that they are set to be completely open if the associated zone $\mathrm{CO}_{2}$ is above $300 \mathrm{ppm}$. As ambient $\mathrm{CO}_{2}$ is set to $400 \mathrm{ppm}$, this ensures that the ventilators in the PSV system are always open. The only difference therefore between the two modelled ventilation systems is the $\mathrm{CO}_{2}$ switching point for the facade ventilators (300ppm for the PSV system and 800ppm for the DCPV) to make the results from the two systems as comparable as possible.

All 12 simulations (three climates at four air-tightness ratings) are run at 12 time-steps per hour, and the vents are therefore assumed to take readings and update their opening level every 5 minutes. All simulations are run for an entire year but as the DCPV vents are set to be constantly open when the associated zone temperature is above $24^{\circ} \mathrm{C}$ or the relative humidity is above $70 \%$, then under these conditions both ventilation systems act similarly and the house will not require heating as the thermostat set-point is $20^{\circ} \mathrm{C}$. To make therefore a more distinct comparison between the two systems' performance the results presented below are only for the simulation periods when the associated zone conditions have not met these temperature/humidity levels, and the DCPV vents are still sensitive to $\mathrm{CO}_{2}$. As it is assumed that the occupants do not open the conventional windows to reduce over-heating until $24^{\circ} \mathrm{C}$ has been reached, then in terms of the results below the conventional windows in the house are considered to be always shut. Table 1 gives a breakdown of the EnergyPlus parameters employed in the model.

\section{Results}

\subsection{Ventilation Flow Rates}

\subsubsection{Stack flow}

With the PSV system, where no control is applied, stack flow rates are strongly related to the environmental driving forces. Figure 6 shows the relationship between ground floor stack flow rate, wind speed and the zone/ambient temperature difference for the Plymouth 0.6ACH@50Pa case during the first 1000 hours of the annual simulation. The flow rate exhibits a strong relationship with wind speed, and a weaker one to the zone/ambient temperature difference.

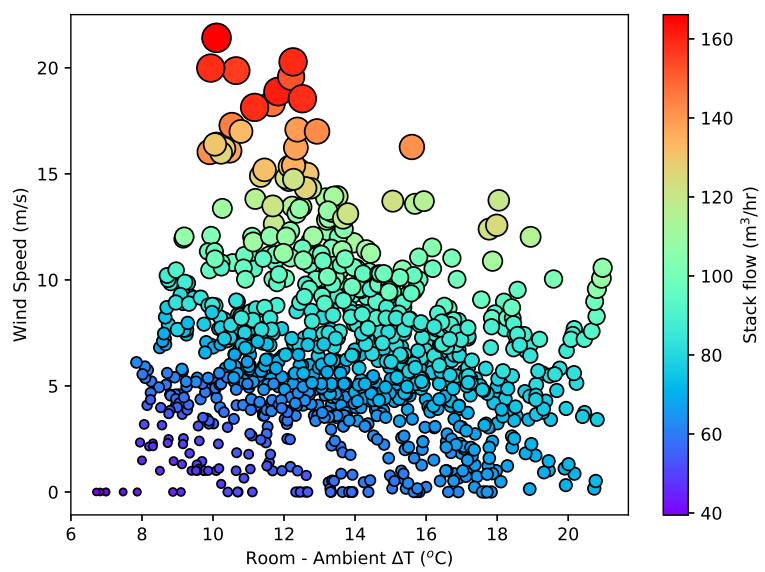

Figure 6: PSV stack flow relationship to wind speed and zone/ambient temperature difference

This strong wind speed relationship means that the flow rates in each location are closely related to the wind conditions at each site: Plymouth, the windiest site, displays the highest stack flow rates; Bergen, with the medium wind speed conditions, displays the second highest; Porto, with the calmest conditions (and the lowest average internal/external temperature difference), the lowest. Figure 7 shows box-and-whisker ${ }^{7}$ plots of the stack flow through the ground and first floor stacks with the PSV system.

\footnotetext{
${ }^{7}$ All box-and-whisker plots presented in this section are organised into each location and shown for each of the 0.6, 1, 2 and 3 ACH@ 50Pa fabric
} 
The ground floor delivers average flows between 58 and $72 \mathrm{~m}^{3} / \mathrm{hr}$, slightly lower than the 63 to $77 \mathrm{~m}^{3} / \mathrm{hr}$ on the first and stack flows on both floors are comparable to the $60 \mathrm{~m}^{3} / \mathrm{hr}$ per floor that could be mandated with a mechanical ventilation system[1], and the $58 \mathrm{~m}^{3} / \mathrm{hr}$ per floor specified for this size of dwelling by the building regulations[2]. This indicates that the simulation approach adopted here for the passive stacks is generating reasonable flow results. Stack flow rates do not increase significantly with increasing fabric air leakage rating, indicating that the limiting factor for the stack flow rate is the dimensions of the stacks themselves and not the fabric leakage area, and that the duct sizings specified in the UK building regulations are therefore appropriate assuming an optimal installation.

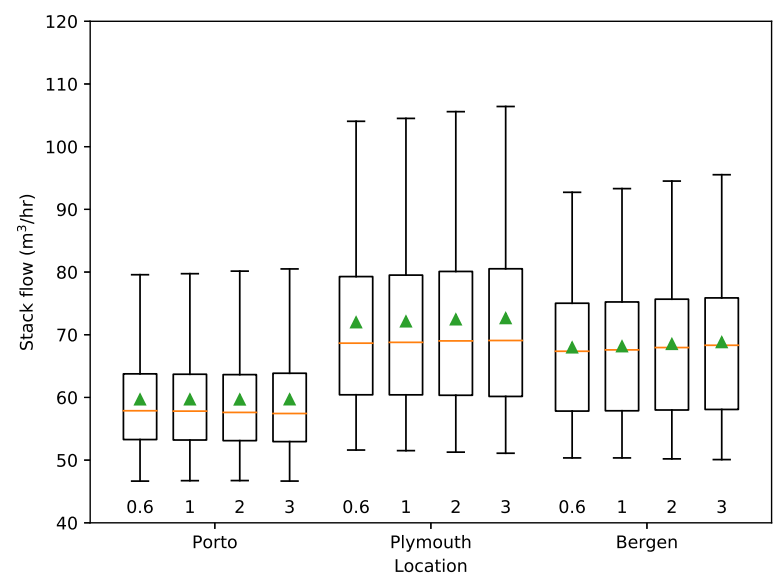

(a) Ground floor

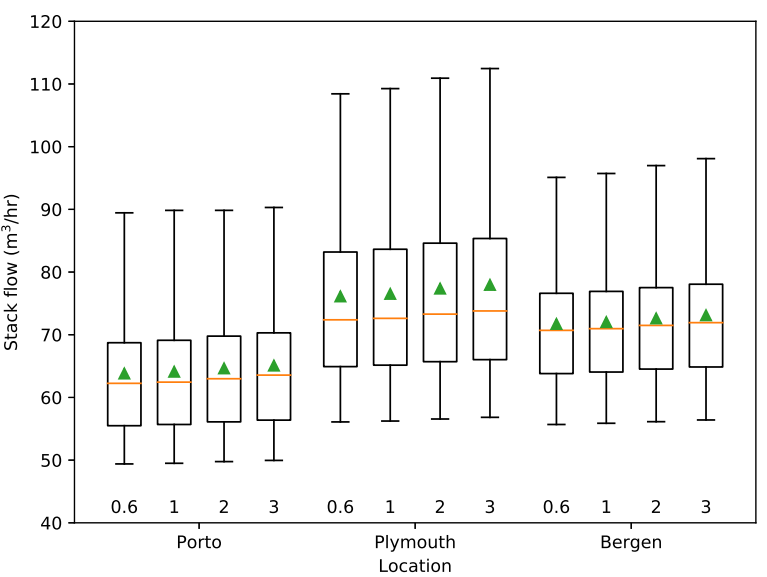

(b) First floor

Figure 7: PSV stack flow rates

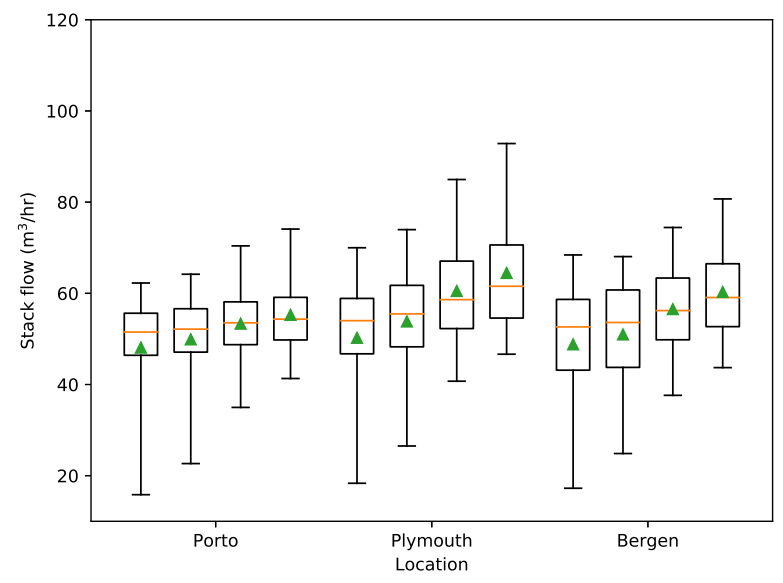

(a) Ground floor

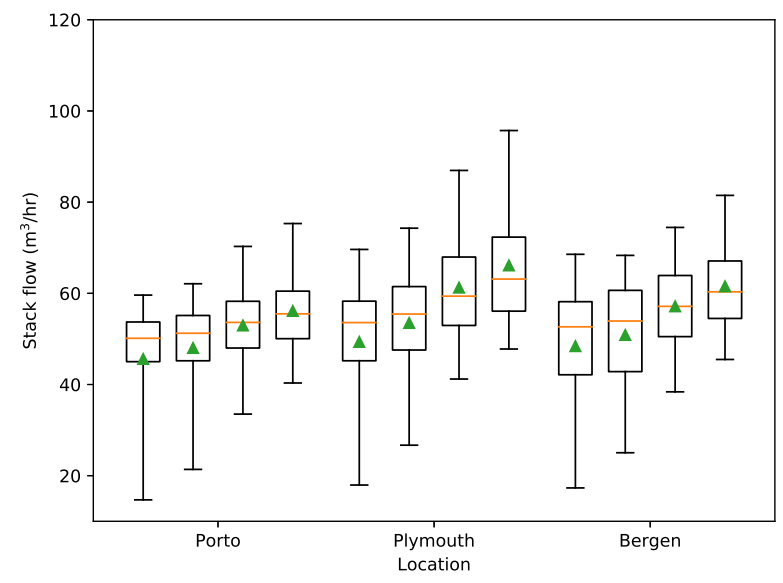

(b) First floor

Figure 8: DCPV stack flow rates

leakage levels. Box limits are at the standard $25^{\text {th }}$ and $75^{\text {th }}$ percentiles. Whiskers are at the $5^{\text {th }}$ and $95^{\text {th }}$ percentiles unless otherwise stated. Median values are displayed with a line. Mean values are displayed with a triangle. 
The flow through the stacks with the DCPV system are shown in figure 8. Average flow rates are reduced slightly compared to the PSV system to between 48 to $64 \mathrm{~m}^{3} / \mathrm{hr}$ on the ground floor and 43 to $65 \mathrm{~m}^{3} / \mathrm{hr}$ on the first. Average flow rates again increase slightly with with windiness of the climate, but on both floors are generally below the recommended whole building design ventilation rate of $58 \mathrm{~m}^{3} / \mathrm{hr}$ per floor[2] with low fabric leakage, and above with high fabric leakage.

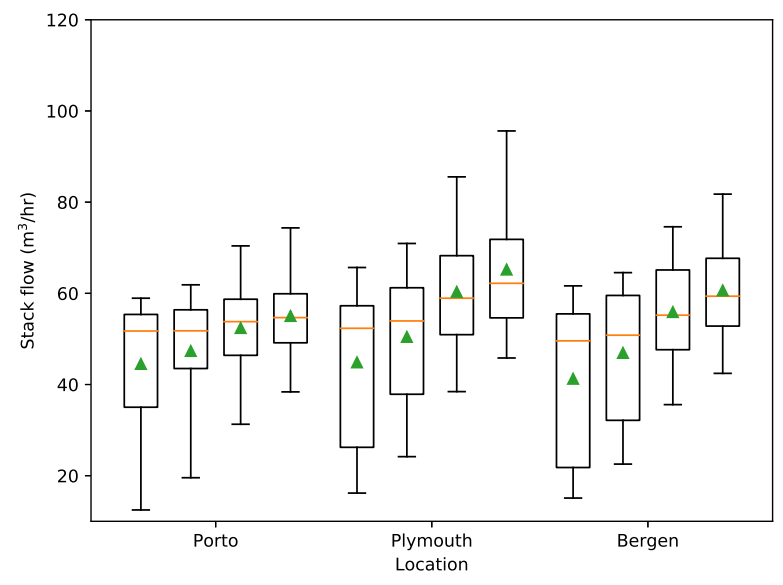

(a) Ground floor

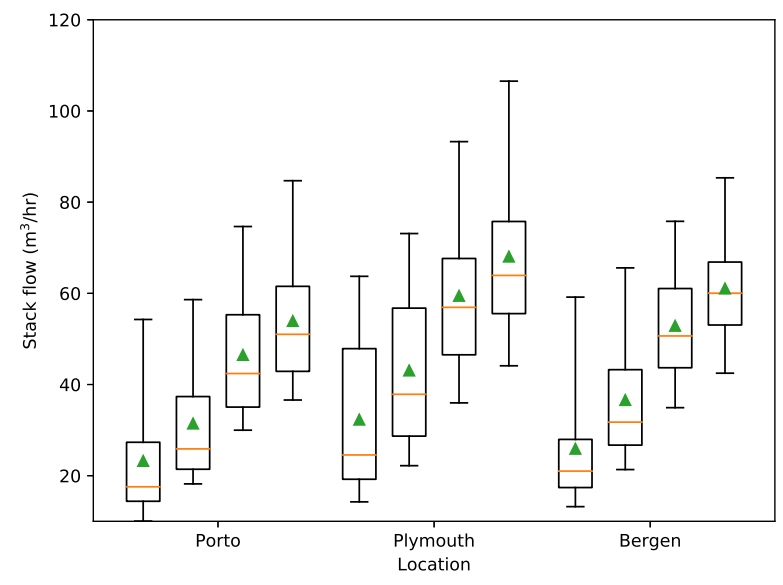

(b) First floor

Figure 9: DCPV stack flow rates (DCPV vents closed)

The lowest flow rates, as represented by the $5^{\text {th }}$ percentile whisker, are much lower with the DCPV system, especially at low fabric leakage levels. These lower values at the $5^{\text {th }}$ percentile correspond to when the DCPV vents on the particular floor are closed. The DCPV stack flow rates when the DCPV vents on that floor are closed are shown in figure 9. With the DCPV vents shut the resistance of the building fabric to air ingress is now the limiting factor for the stack flow, which now increases significantly with fabric air leakage rating. At $0.6 \mathrm{ACH} @ 50 \mathrm{~Pa}$ the average stack flow is reduced to approximately 42 to $43 \mathrm{~m}^{3} / \mathrm{hr}$ on the ground floor and 22 to $33 \mathrm{~m}^{3} / \mathrm{hr}$ on the first. At $3 \mathrm{ACH} @ 50 \mathrm{~Pa}$ average flow rates approach those delivered with the PSV system.

\subsubsection{Facade ventilator flow}

The hourly sums of the total incoming flow ${ }^{8}$ through all the periphery ventilators on the ground and first floors with the PSV system are shown in figure 10. Despite the stack flows (figure 7) being slightly higher on the first floor the vent inflow is far higher on the ground floor. Average inflows on the ground floor are between 78 and $105 \mathrm{~m}^{3} / \mathrm{hr}$. On the first floor average flows are between 22 and $50 \mathrm{~m}^{3} / \mathrm{hr}$. On both floors vent inflow declines with increasing fabric leakage as more of the air ingress is supplied through the fabric rather than the vents.

The marked difference between the two floors is due to the buoyancy driven flow up the stairwell from the ground to first floor. This stairwell flow decreases the interior pressure on the ground floor, increasing air inflow via the ground floor vents, and increases pressure on the first floor, generating the opposite effect. Figure 11 shows the net stairwell flow from the ground to first floors.

\footnotetext{
${ }^{8}$ For each time step of the simulation flow through an aperture can be in either direction. The stairwell flows presented in this section are the net flow (positive values are ground to first floor). The vent inflow and outflow results are considered separately (each therefore only has positive values).
} 


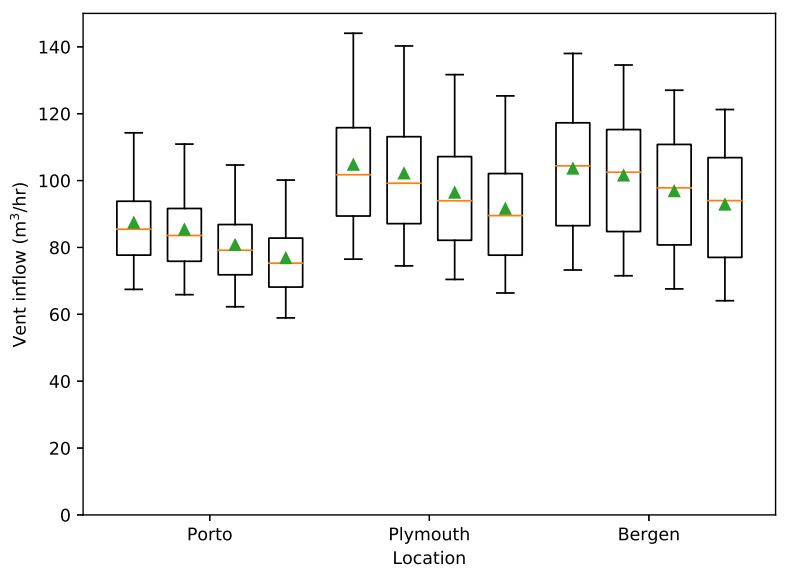

(a) Ground floor

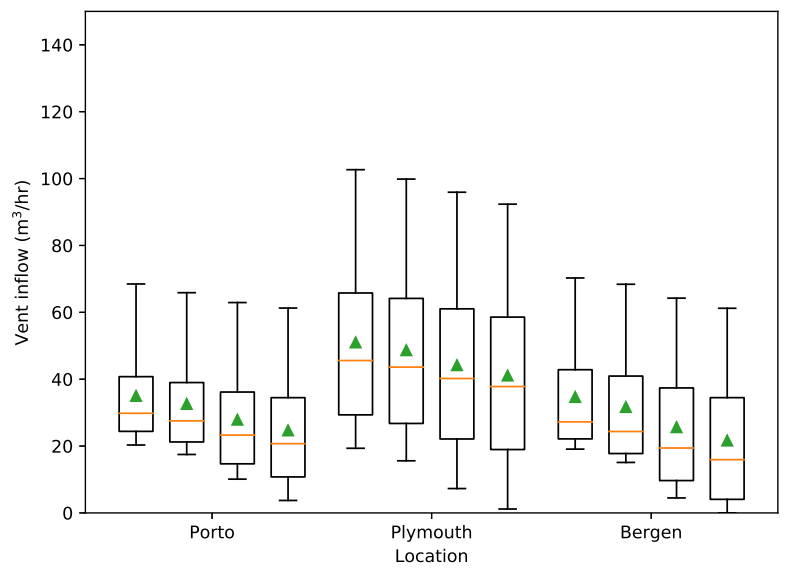

(b) First floor

Figure 10: PSV vent inflow

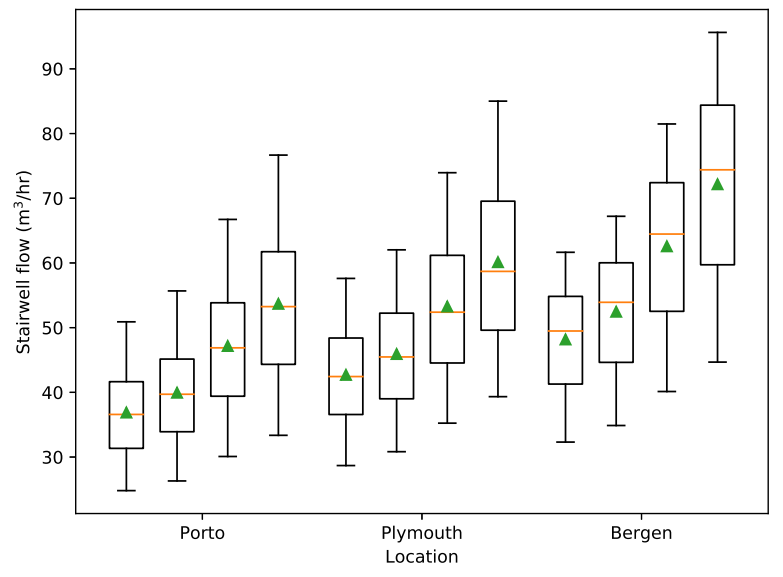

Figure 11: PSV stairwell flow $\left(\mathrm{m}^{3} / \mathrm{hr}\right)$ [positive values represent ground to first floor]

Net stairwell flow from ground to first floor averages between 44 and $70 \mathrm{~m}^{3} / \mathrm{hr}$ and increases significantly with fabric leakage rating, indicating that the flow up the stairwell is being restricted by the opening area of the ground floor facade ventilators and fabric leakage. As the average flow via the stairwell into the first floor, coupled with the average vent inflow into the first floor, is greater than the average first floor stack exit flow this indicates an alternative egress point, which in this simulation model can only the be facade ventilators/fabric leakage on the first floor. Figure 12 shows the hourly sums of the outflows through the ground and first floor ventilators with the PSV system.

Outflow on the ground floor is minor whilst on the first outflow is indeed significant. On both floors outflow increases with increasing fabric air-leakage rating and with the increasing windiness of the climate. This latter relationship suggests that a cross-ventilation flow pattern (figure 1c) is being created under windier conditions and this is confirmed in figure 13 which shows the relationship between wind speed and first floor ventilator outflow.

This additional air egress through the ventilators, which will be augmented by flow through the facade depending on fabric leakage rating, is fed by the increased flow into the ground floor and rising up the stairwell, and by increased 
ventilator flow on the windward side of the building and will result in increased space heating consumption in cold weather.

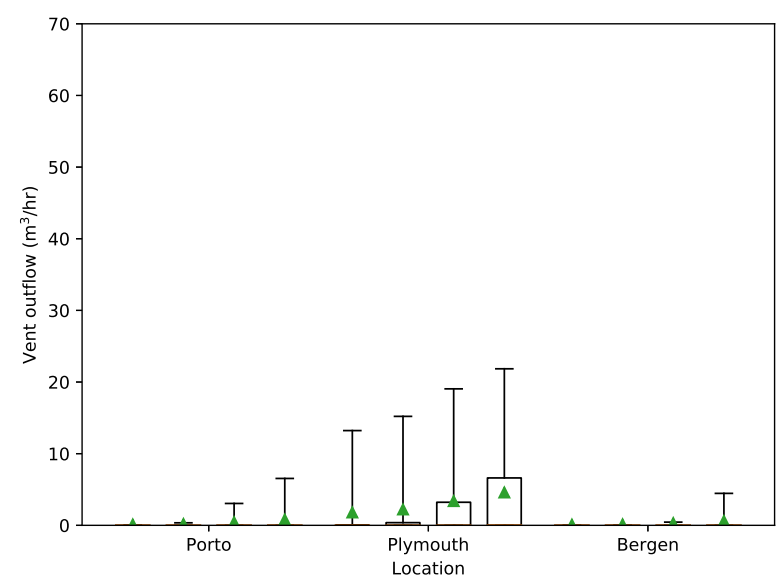

(a) Ground floor

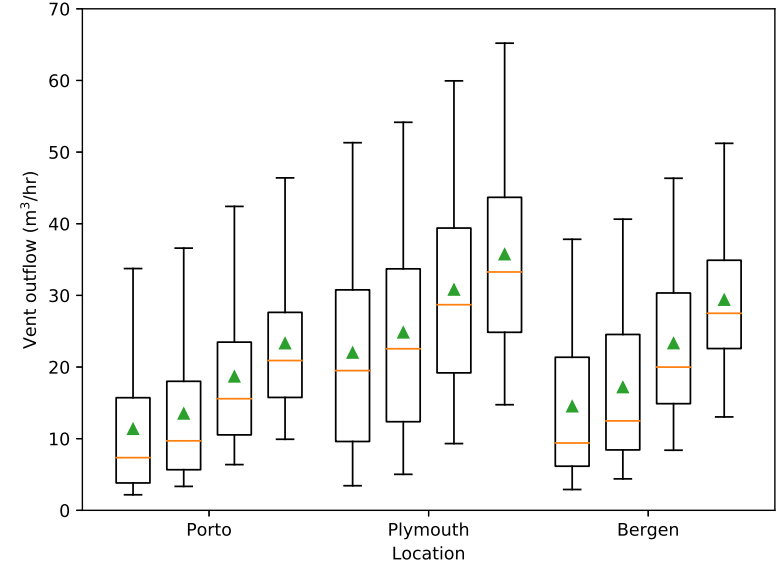

(b) First floor

Figure 12: PSV facade ventilator outflow

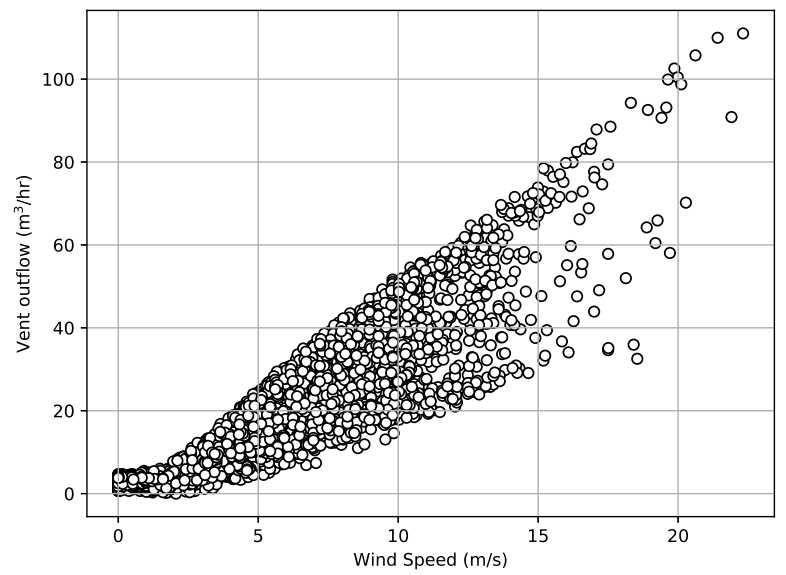

Figure 13: PSV first floor vent outflow with wind speed

Ventilator inflow (figure 14) with the DCPV system is much more consistent across the two floors, averaging between 20 and $40 \mathrm{~m}^{3} / \mathrm{hr}$ on the ground floor and 30 and $44 \mathrm{~m}^{3} / \mathrm{hr}$ on the first. Average flow rates are lower than with the PSV system due to the closing action of the ventilators, which also reduces the $5^{\text {th }}$ and $25^{\text {th }}$ percentile values to zero in all scenarios. As with the PSV system, vent inflow reduces with increasing fabric leakage rating as the fabric provides an increasing proportion of the air ingress. The slightly higher flow on the first floor, a reverse of the PSV system, is due to the longer periods of occupancy on the first floor raising the $\mathrm{CO}_{2}$ level to above 800ppm and causing the ventilators to open. 


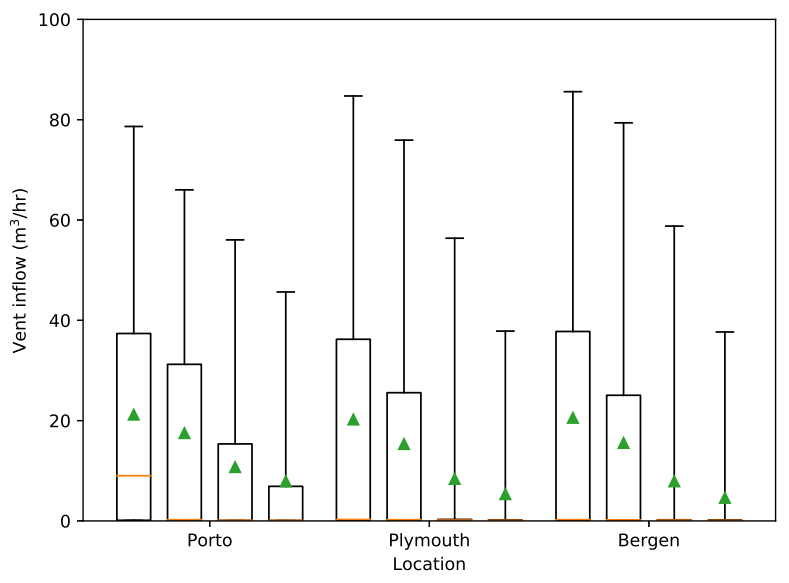

(a) Ground floor

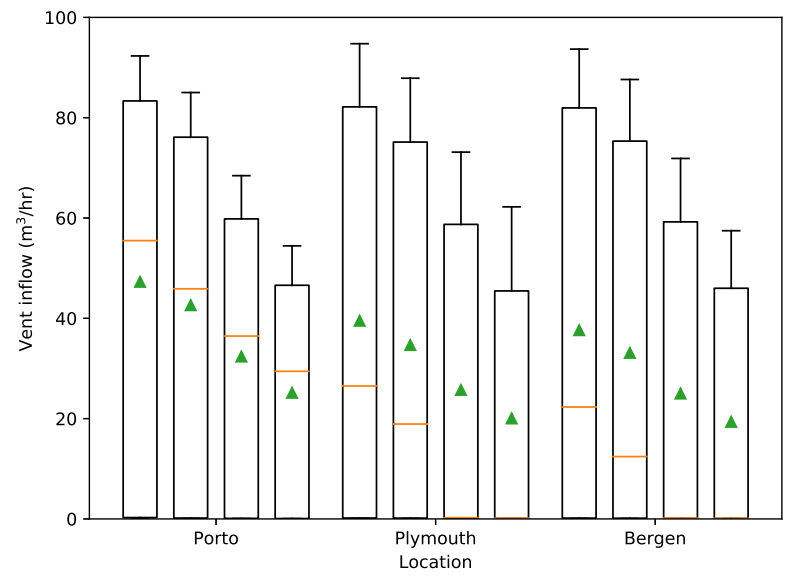

(b) First floor

Figure 14: DCPV facade ventilator inflow

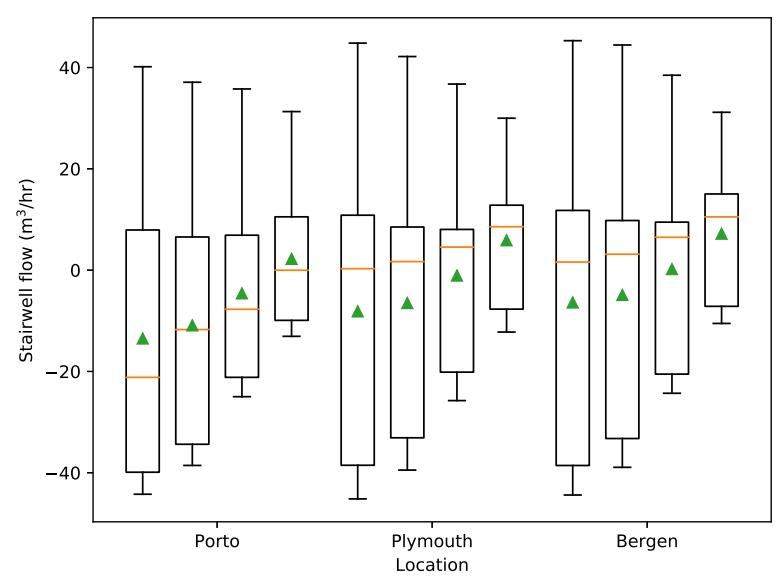

Figure 15: DCPV stairwell flow $\left(\mathrm{m}^{3} / \mathrm{hr}\right)$ [positive values represent ground to first floor]

As the flows across the two floors appear more balanced with the DCPV system it could be assumed that net stairwell flow has been reduced. Figure 15 shows the net stairwell flow from ground to first floors (positive values are ground to first).

Flow up the stairs is now more or less balanced by flow down the stairs with average net flow of less than $12 \mathrm{~m}^{3} / \mathrm{hr}$ in all scenarios. Significant directional flows do still occur however. When the occupancy downstairs opens the vents air moves upstairs, and when occupancy upstairs open the vents air moves downstairs. As upstairs is occupied for a greater proportion of the week than downstairs net flow is slightly negative at low fabric leakage ratings. At higher fabric leakage rating the natural buoyancy flow seen with the PSV system begins to reassert itself.

Figure 16 shows the outward flow through the ground and first floor ventilators. The minimal average outflow on the ground floor with the PSV system has been further reduced by the DCPV system, and the more significant outflow on the first floor has also been significantly reduced from between 20 to $30 \mathrm{~m}^{3} / \mathrm{hr}$ to between 0 to $2 \mathrm{~m}^{3} / \mathrm{hr}$.

The DCPV system therefore appears effective at reducing net stairwell flow (figure $1 \mathrm{~b}$ ) and reducing vent outflow 
on the first floor by stairwell flow and cross-ventilation (figure 1c) even at the highest fabric leakage rating.

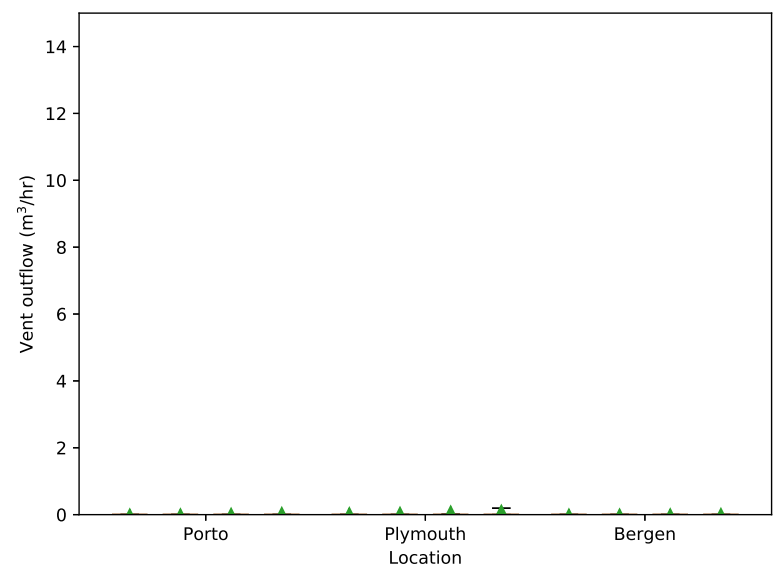

(a) Ground floor

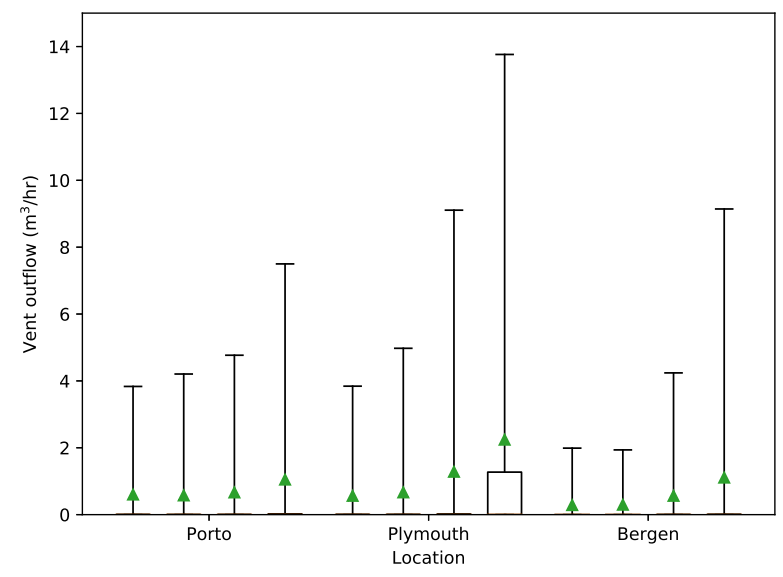

(b) First floor

Figure 16: DCPV facade ventilator outflow

\subsection{Indoor Air Quality}

3.2.1. $\mathrm{CO}_{2}$ levels

Ground floor $\mathrm{CO}_{2}$ levels and occupancy levels with both the PSV and DCPV systems over the course of three days at the beginning of the simulation period ( $1^{s t}$ to the $3^{\text {rd }}$ of January) can be seen in figure 17 for the Plymouth 0.6ACH@50Pa scenario. With the PSV system $\mathrm{CO}_{2}$ levels drop to the ambient 400ppm between occupied periods. With the DCPV system levels decay at different rates depending on the level of occupancy on the upper floor. At night, flow down the stairwell from the occupied upper floor maintains higher $\mathrm{CO}_{2}$ levels on the unoccupied ground floor with levels only dropping to 750ppm. During weekdays, when there is no occupancy in the building, levels drop to between 450 to 500ppm. At all times $\mathrm{CO}_{2}$ takes longer to clear with the DCPV system as the DCPV vents close at 800ppm and the remaining $\mathrm{CO}_{2}$ takes longer to purge. Levels also rise quicker with the DCPV system at the start of an occupied period as the vents do not open until 800ppm is reached.

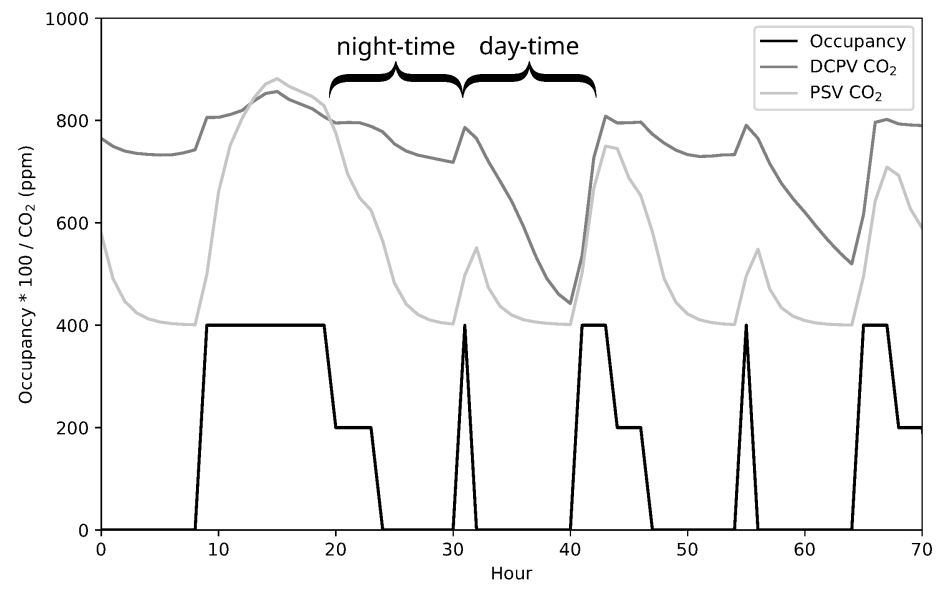

Figure 17: Ground floor $\mathrm{CO}_{2}$ levels with the DCPV and PSV systems 
The hourly $\mathrm{CO}_{2}$ levels with the PSV system on the ground and first floors are shown in box-and-whisker format (whiskers at the minimum and maximum values) in figure 18.

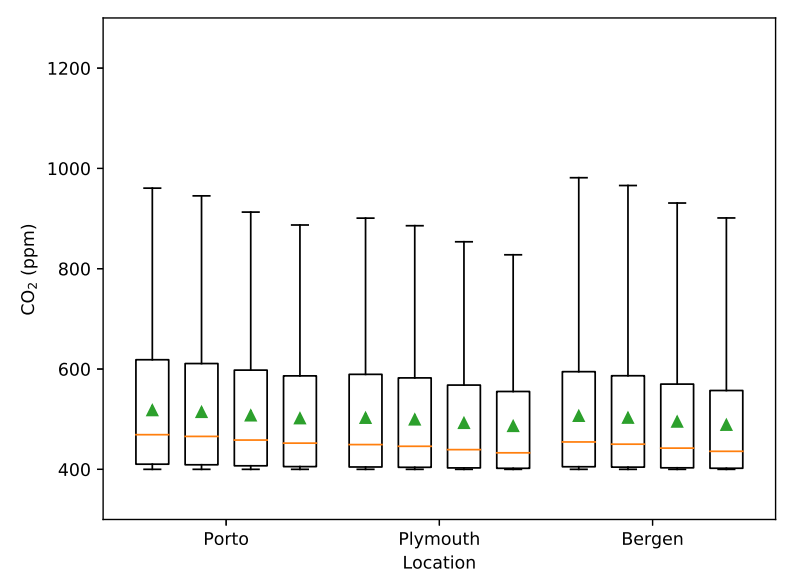

(a) Ground floor

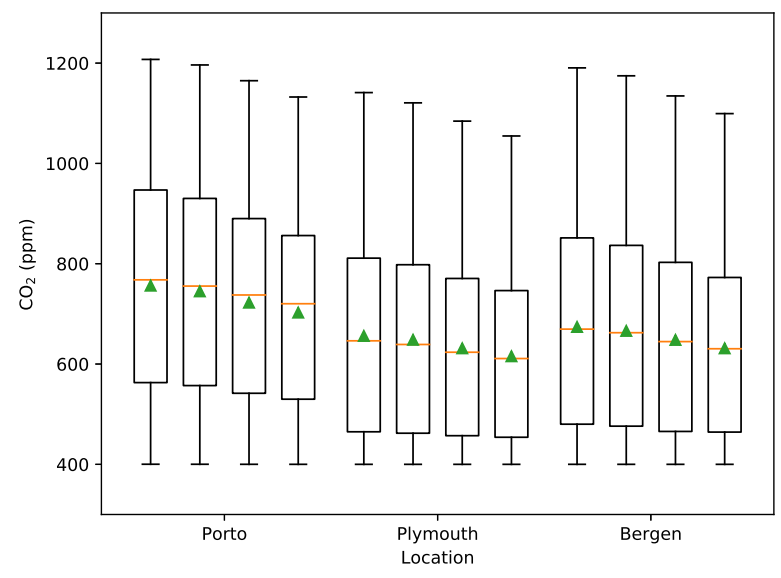

(b) First floor

Figure 18: $\mathrm{PSV} \mathrm{CO}_{2}$ levels

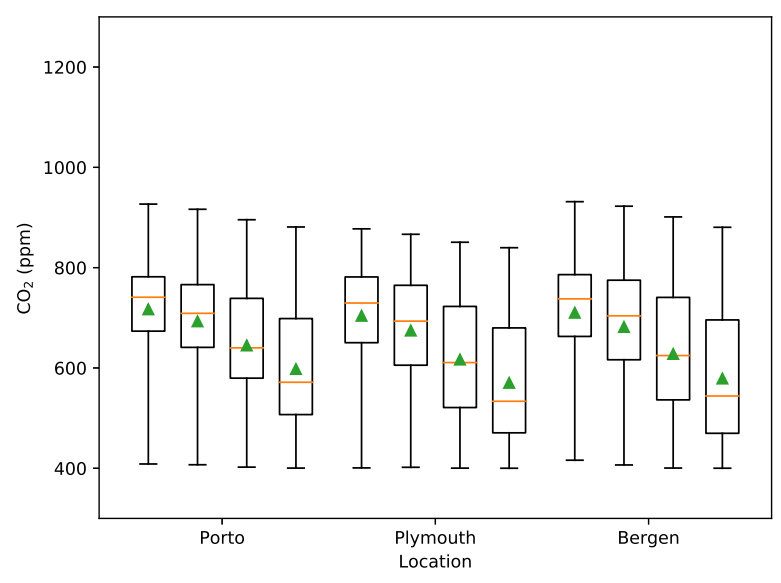

(a) Ground floor

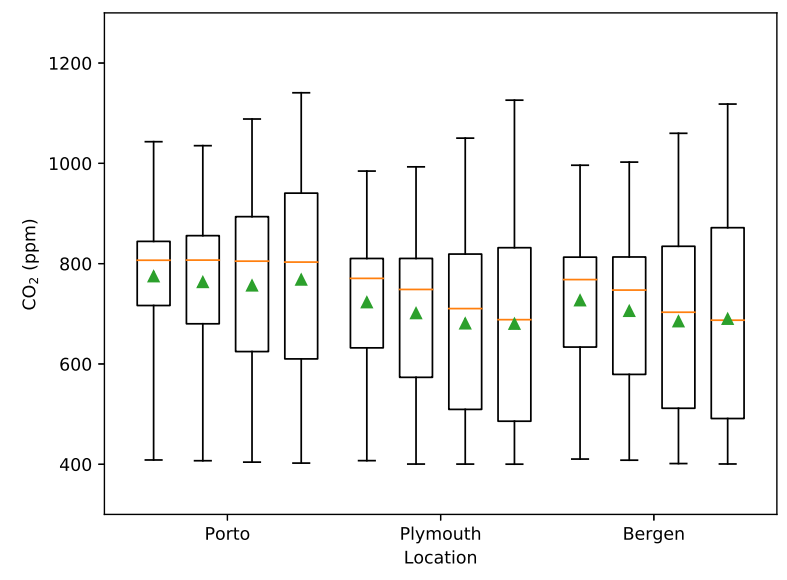

(b) First floor

Figure 19: DCPV $\mathrm{CO}_{2}$ levels

Average $\mathrm{CO}_{2}$ levels are around 500ppm on the ground floor and around $650 \mathrm{ppm}$ on the first. The lower levels on the ground floor are a result of the greater ground floor vent/fabric inflow. Levels reduce with greater fabric air leakage, and are overall the lowest in the windiest climate (Plymouth) due to the greater fresh air ingress caused by the higher wind pressure differentials. Average $\mathrm{CO}_{2}$ levels with the DCPV system (figure 19) are slightly higher: around 650ppm on the ground floor and 700ppm on the first.

For both systems the 1000ppm upper limit of the EN 13779 standard is only breached on the first floor. The percentage of simulation time that the first floor exhibits $\mathrm{CO}_{2}$ levels above $1000 \mathrm{ppm}$ is shown in figure 20 . 
With the PSV system the 1000ppm level is exceeded most often in the warmest and least windiest climate (Porto) as the driving forces for ventilation are the weakest and ventilation levels through the building are generally lower (figure 7). Also, the percentage of time reduces with increasing fabric leakage as more fabric ingress limits $\mathrm{CO}_{2}$ accumulation. With the DCPV system occurrences of levels above 1000ppm are very rare at low fabric leakage levels but increase with higher fabric leakage levels. At these higher leakage rates buoyant flow up the stairs begins to dominate due to the uncontrolled fabric air ingress and flow into the first floor from outside is limited; in effect the DCPV system begins to act more like the PSV.

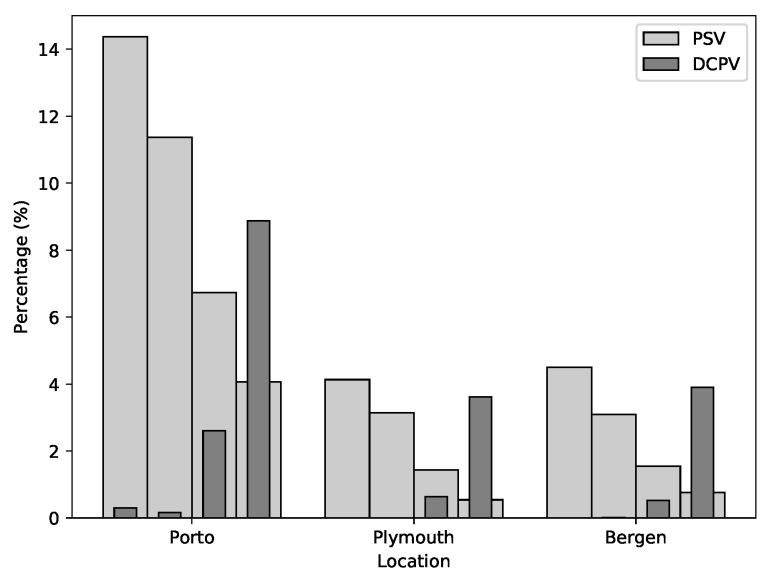

Figure 20: Percentage of simulation period first floor $\mathrm{CO}_{2}$ levels breach 1000ppm

Both systems do however appear to offer satisfactory IAQ, with average and peak $\mathrm{CO}_{2}$ levels in accordance with monitored data of dwellings with mechanical systems designed to deliver an appropriate ventilation flow rate [16]. Only in the morning on the ground floor does the DCPV system deliver significantly higher $\mathrm{CO}_{2}$ levels due to the overnight supply of air to the ground floor from the occupied first.

\subsubsection{Humidity}

As no discrete internal sources of moisture have been modelled, the DCPV system has no direct impact on RH levels. The DCPV system does however create a greater proportion of the year where the zone temperatures are between 20 and $24^{\circ} \mathrm{C}$ as solar and occupant gains more easily overcome the lower building heat loses (section 3.3.1). Humidity levels are therefore on average slightly lower than with the PSV system, and never rise above the $70 \%$ set-point that causes the DCPV vents to open.

\subsection{Energy Performance}

\subsubsection{Space heating performance}

Box-and-whisker plots of hourly space heating consumption with the PSV system are shown in figure 21 . The space heating requirements of the two floors are markedly different. Average heating requirement ranges from 20 to $600 \mathrm{~W}$ on the ground floor and 0 to $200 \mathrm{~W}$ on the first. Average heating increases with fabric leakage rate and the coldness of the climate. $95^{\text {th }}$ percentile values range from 350 to $1600 \mathrm{~W}$ on the ground floor and 0 to $450 \mathrm{~W}$ on the first. Again these peak values increase with fabric leakage and coldness of the climate.

The difference between the two floors is again a result of the net stairwell flow from the ground to first floors. Ventilation flow up the stairwell increases the fresh air ingress on the ground floor and increases local space heating requirement. First floor heating consumption is not increased by this flow however as the simulation model is set up so that each zone is heated to a constant minimum of $20^{\circ} \mathrm{C}$ and air entering the first floor from the ground is therefore 
already at or above the heating set-point temperature. This airflow does however reduce fresh air ingress on the first floor, suppressing first floor heating requirement.

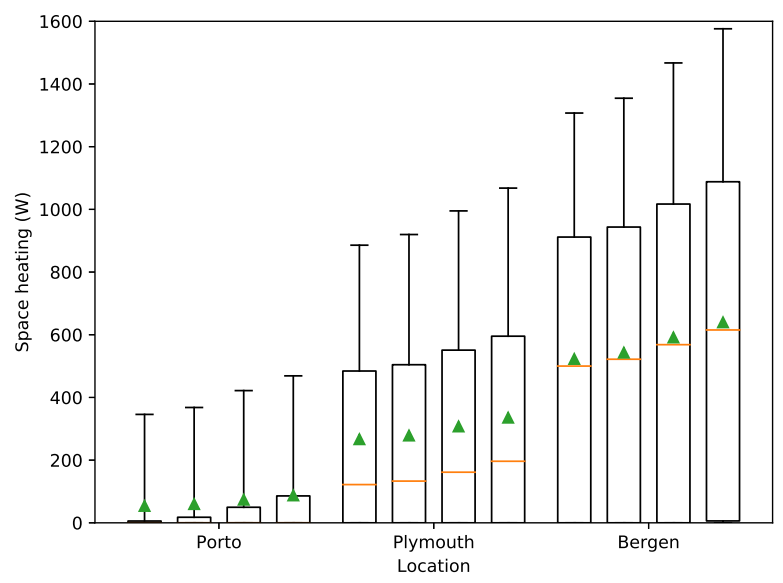

(a) Ground floor

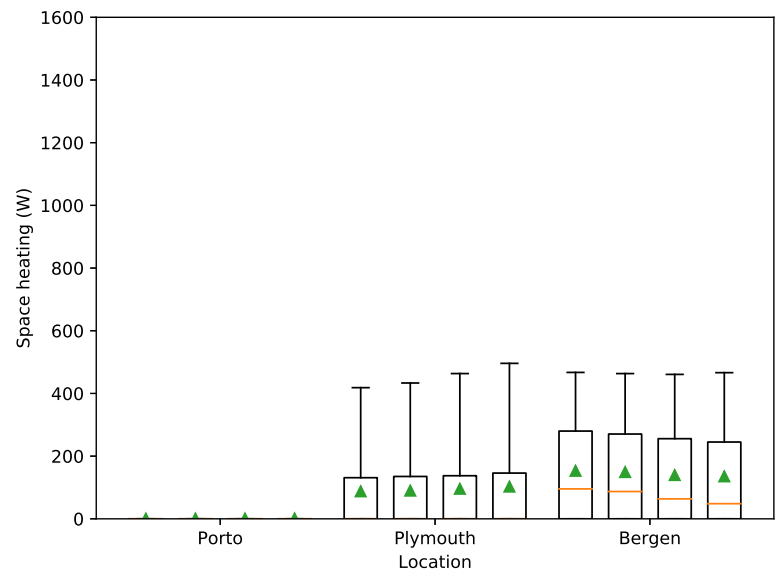

(b) First floor

Figure 21: PSV space heating consumption (Watts)

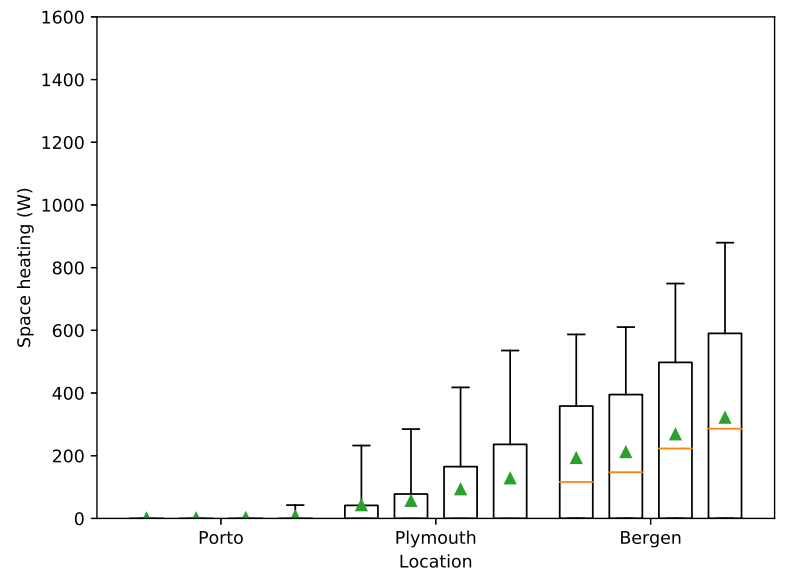

(a) Ground floor

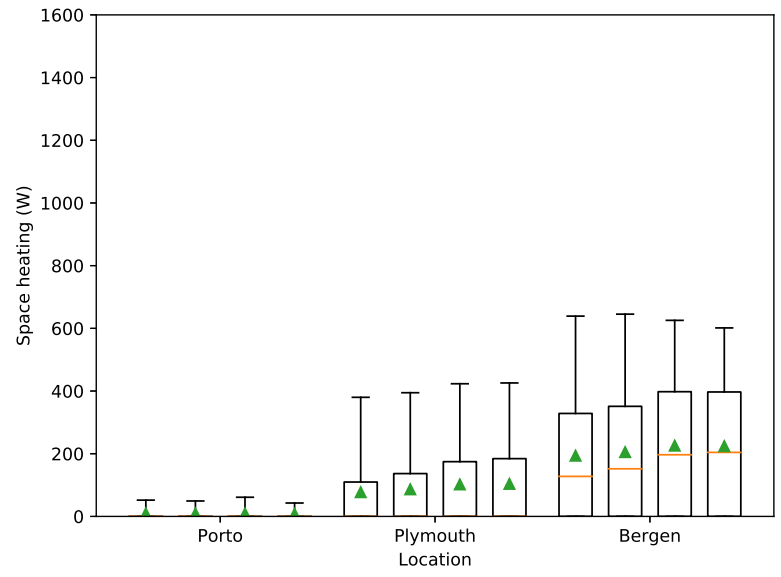

(b) First floor

Figure 22: DCPV space heating consumption (Watts)

The space heating consumption with the DCPV system is shown in figure 22. Average values range from 0 to $300 \mathrm{~W}$ on the ground floor and between 0 to $220 \mathrm{~W}$ on the first. Peak $95^{\text {th }}$ percentile values range from 0 to $900 \mathrm{~W}$ on the ground and 30 to $700 \mathrm{~W}$ on the first. Heating requirement across the floors is now much more consistent due to the reduction in the net stairwell flow from the ground to first floors. Excess air ingress on the ground floor is now reduced, and fresh air ingress is no longer being suppressed on the first. This makes the first floor space heating consumption actually slightly higher with the DCPV system, but much lower on the ground floor. On the ground floor both average and peak heating values again increase with fabric leakage and coldness of climate. On the first floor this relationship is 
however not so clear as higher fabric leakage causes more to enter the ground floor, increasing stairwell flow, reducing first floor air ingress which can reduce first floor heating consumption.

The annual space heating requirements for the whole house with the PSV and DCPV systems are shown in figure 23 (for reference the red line shows the $15 \mathrm{kWh} / \mathrm{m}^{2}$. a mandated by the PassivHouse standard[4]). Space heating ranges with the PSV system between 3 to $60 \mathrm{kWh} / \mathrm{m}^{2} \cdot$ a and again rises with fabric leakage value and the coldness of the climate. With the DCPV system space heating ranges from 0 to $35 \mathrm{kWh} / \mathrm{m}^{2} \cdot \mathrm{a}$. Absolute energy savings are the highest in the coldest climate (Bergen) with savings of of around $25 \mathrm{kWh} / \mathrm{m}^{2} \cdot \mathrm{a}$.

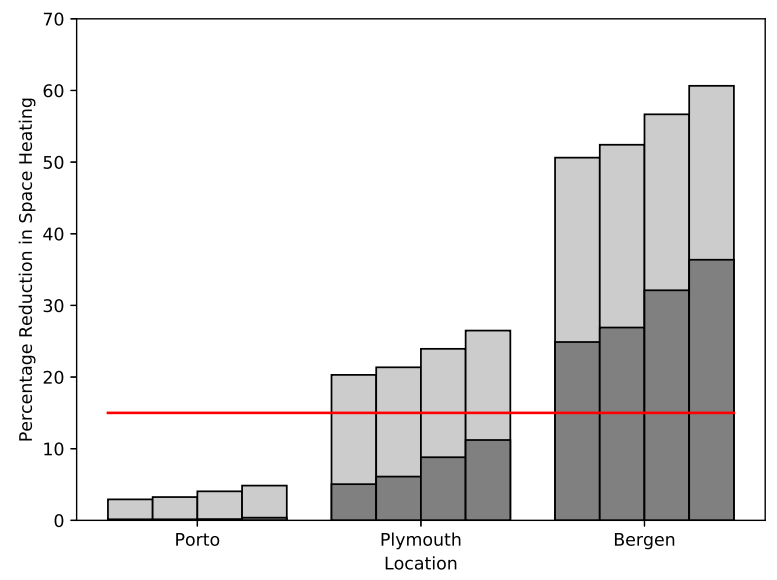

Figure 23: PSV and DCPV space heating consumption $\left(\mathrm{kWh} / \mathrm{m}^{2} \cdot \mathrm{a}\right)$

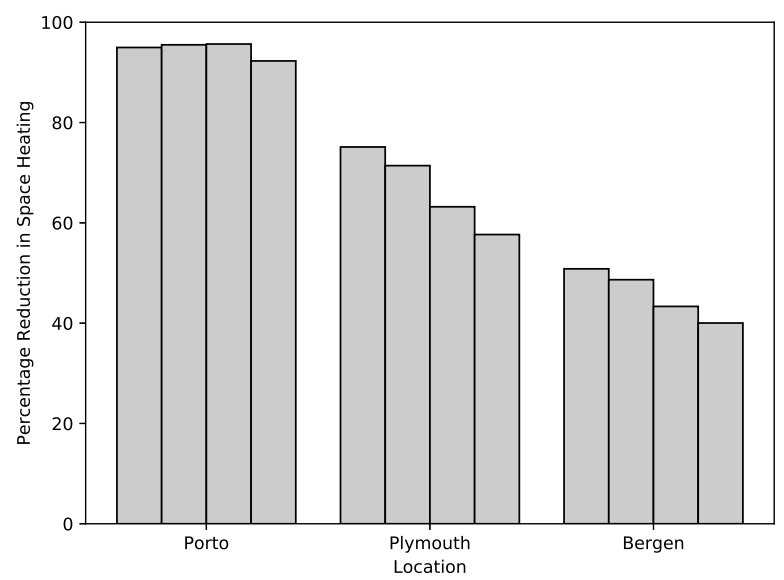

Figure 24: Percentage space heating reduction

Figure 24 shows the percentage reduction in space heating with the DCPV system compared to the PSV system. These reductions range from 40 to $95 \%$ and reduce with increasing fabric leakage as the DCPV facade ventilators are increasingly bypassed by fabric leakage. However, even at the highest fabric leakage rate, where the stacks flows are very similar with the DCPV and PSV systems, energy savings of over $40 \%$ are still delivered. This is due to the reduction of the stairwell and cross-ventilation flows that still occurs at the highest fabric leakage rating.

Percentage energy reductions are greatest in Porto due to the milder ambient temperatures. The milder temperatures 
are important as the DCPV system primarily allows ventilation when there is occupancy in the associated zone that raises the internal $\mathrm{CO}_{2}$ to above 800ppm. These internal occupant heat gains offset the ventilation heat losses and as the winter temperature in Porto are generally milder, the potential ventilation heat loss is generally lower and these internal heat gains therefore offset a greater percentage of the ventilation heat loss.

\section{Conclusions}

In this comparative simulation analysis of two natural ventilation strategies: a conventional PSV system with facade ventilators and a PSV system with active ventilation demand controlled facade ventilators (a DCPV system), the DCPV system has been shown to have the potential to regulate ventilation flow patterns, maintain IAQ and reduce building space heating consumption.

In terms of flow patterns, instead of a consistent flow up the stairwell, which is in effect acting as an internal stack, with the conventional PSV system the DCPV system delivers stairwell flow which changes direction in response to occupancy and the opening of the ventilation demand control ventilators. With occupancy downstairs the lower vents open and air enters through the ground floor ventilators to supply not only the ground floor stack, but rises up the stairwell to supply the first floor stack. With upper floor occupancy the opposite is the case. These changes to the stairwell flow pattern are important as it has an impact on the related $\mathrm{CO}_{2}$ and energy performance metrics.

Generally, $\mathrm{CO}_{2}$ levels with both systems can be considered adequate, with rare occurrences of $\mathrm{CO}_{2}$ above $1000 \mathrm{ppm}$, especially when coupled with a particular fabric leakage level (high leakage for the PSV system and low leakage for the DCPV system). Although the DCPV system does deliver overall higher average $\mathrm{CO}_{2}$ levels, these higher levels mostly occur in spaces when they are unoccupied. During occupation $\mathrm{CO}_{2}$ levels rise to 800ppm and the DCPV facade ventilators open, limiting peak $\mathrm{CO}_{2}$ to a similar level as the PSV system. The changes in the stairwell flow regime also makes $\mathrm{CO}_{2}$ levels more consistent across the two floors with the DCPV system.

Generally, space heating reductions depend on climate and fabric leakage level, and are a result of two factors: reduced ventilation ingress when the DCPV facade ventilators are shut, and the regulation of stairwell flow and subsequent reduction in uncontrolled air egress on the first floor. The former is most effective at low fabric leakage ratings, the latter applies at all simulated fabric leakage rates. Space heating percentage reductions are greatest in the warmest and calmest climate (Porto) where reductions with a low fabric leakage rating can reach 95\%, albeit from a low base PSV system consumption of around $4 \mathrm{kWh} / \mathrm{m}^{2} \cdot$ a: a figure low enough to question the economic viability of additional energy saving measures. Absolute reductions are greatest in the coldest climate (Bergen) where around $25 \mathrm{kWh} / \mathrm{m}^{2} \cdot \mathrm{a}$ can be saved. In this colder climate it may however require more sensitive placement of the facade ventilators to avoid thermal discomfort from direct cold air ingress. In Plymouth, with a climate representative of the Atlantic Central climate zone that is cold enough to have a significant heating season but mild enough in winter to mitigate thermal discomfort resulting from cold air ingress, percentage reductions range between 58 and $75 \%$ with an absolute reduction of around $15 \mathrm{kWh} / \mathrm{m}^{2} \cdot$ a. According to these simulations it may even be possible in this climate zone to reduce space heating consumption to below the PassivHaus mandated $15 \mathrm{kWh} / \mathrm{m}^{2} \cdot$ a for all the modelled fabric air-leakage levels.

Although significant further work, including experimental field trials, will be required to answer questions such as how well the DCPV system deals with other internal pollutants, or what effect a simulation model with separate room zones has on the system's performance, the DCPV system, as presented and analysed here, does appear to merit further investigation and development.

\section{References}

[1] K. Mead, R. Brylewski, Passivhaus Primer: Introduction-An aid to Understanding the Key Principles of the Passivhaus Standard (2010).

[2] NBS, Approved Document F - Ventilation (2010 edition incorporating 2010 and 2013 amendments), Tech. rep. (Oct. 2015).

[3] R. Stephen, L. Parkins, M. Woolliscroft, Passive stack ventilation systems: design and installation, Citeseer, 1994. 
[4] J. Cotterell, A. Dadeby, Passivhaus Handbook: A Practical Guide to Constructing and Refurbishing Buildings for Ultra-low-energy Performance, Green, 2012.

[5] D. B. Crawley, C. O. Pedersen, L. K. Lawrie, F. C. Winkelmann, EnergyPlus: energy simulation program, ASHRAE journal 42 (4) (2000) 49.

[6] R. Southall, F. Biljecki, The VI-Suite: a set of environmental analysis tools with geospatial data applications, Open Geospatial Data, Software and Standards 2 (1) (2017) 23. doi:10.1186/s40965-017-0036-1. URL https : //doi.org/10.1186/s40965-017-0036-1

[7] U. DoE, Energyplus engineering reference, The reference to energyplus calculations.

[8] L. Gu, Airflow network modeling in EnergyPlus, in: Building Simulation, Vol. 10, 2007.

[9] P. G. Ellis, P. A. Torcellini, D. Crawley, Simulation of energy management systems in EnergyPlus, Tech. rep., National Renewable Energy Laboratory (NREL), Golden, CO. (2008).

[10] M. J. Metzger, R. G. H. Bunce, R. H. Jongman, C. Mücher, J. W. Watkins, A climatic stratification of the environment of Europe, Global ecology and biogeography 14 (6) (2005) 549-563.

[11] R. Jongman, R. Bunce, M. Metzger, C. Mücher, D. Howard, V. Mateus, Objectives and applications of a statistical environmental stratification of Europe, Landscape ecology 21 (3) (2006) 409-419.

[12] Z. J. Zhai, M.-H. Johnson, M. Krarti, Assessment of natural and hybrid ventilation models in whole-building energy simulations, Energy and Buildings 43 (9) (2011) 2251-2261.

[13] N. M. Mateus, A. Pinto, G. C. da Graça, Validation of EnergyPlus thermal simulation of a double skin naturally and mechanically ventilated test cell, Energy and Buildings 75 (2014) 511-522.

[14] S. Dutton, L. Shao, S. Riffat, Validation and Parametric Aanalysis of EnergyPlus: Air Flow Network Model Using CONTAM, Proceedings of SimBuild 3 (1) (2008) 124-131.

URL http://www. ibpsa-usa.org/index.php/ibpusa/article/view/244

[15] T. Schulze, U. Eicker, Controlled natural ventilation for energy efficient buildings, Energy and Buildings 56 (2013) 221-232.

[16] T. Sharpe, I. Mawditt, R. Gupta, G. McGill, M. Gregg, Characteristics and performance of MVHR systems A meta study of MVHR systems used in the Innovate UK Building Performance Evaluation Programme.

[17] M. H. Sherman, D. J. Dickerhoff, Airtightness of US dwellings, Transactions-American Society Of Heating Refrigerating And Air Conditioning Engineers 104 (1998) 1359-1367.

[18] J. Straube, E. Burnett, Building Science for Building Enclosures, Building Science Press, 2005. URL https : //books.google.co.uk/books?id=V8DiAAAAMAAJ

[19] H. Awbi, Ventilation of Buildings, E\&FN SPON.

[20] M. Swami, S. Chandra, Correlations for pressure distribution on buildings and calculation of natural-ventilation airflow, ASHRAE transactions 94 (3112) (1988) 243-266.

[21] R. Ramponi, D. Cóstola, A. Angelotti, B. Blocken, J. Hensen, Evaluation of wind-driven ventilation in building energy simulation: sensitivity to pressure coefficients, in: Cleantech for sustainable buildings conference. Lausanne, Switzerland, 2011, pp. 949-954.

[22] L. S. Marks, T. Baumeister, Mechanical engineers' handbook, McGraw-Hill, 1916. 
[23] E. CEN, 13779, Ventilation for non-residential buildings-performance requirements for ventilation and roomconditioning systems. Brussels, Belgium.

[24] A. Standard, ANsI, ASHRAE Standard 62.

[25] J. Laverge, N. V. D. Bossche, N. Heijmans, A. Janssens, Energy saving potential and repercussions on indoor air quality of demand controlled residential ventilation strategies, Building and Environment 46 (7) (2011) 14971503. doi:10.1016/j.buildenv.2011.01.023.

URL http://www. sciencedirect.com/science/article/pii/s0360132311000333

[26] T. R. Nielsen, C. Drivsholm, Energy efficient demand controlled ventilation in single family houses, Energy and Buildings 42 (11) (2010) 1995-1998. doi:10.1016/j.enbuild.2010.06.006. URL http: //wWw. sciencedirect.com/science/article/pii/s0378778810001994

[27] T. Lu, X. Lü, M. Viljanen, A novel and dynamic demand-controlled ventilation strategy for CO 2 control and energy saving in buildings, Energy and buildings 43 (9) (2011) 2499-2508. 